\title{
Extended retinal tamponade in the treatment of retinal detachment with proliferative vitreoretinopathy
}

\author{
WALTER H STERN, ROBERT N JOHNSON, ALEXANDER R IRVINE, \\ MICHAEL E BARRICKS, BLAINE S BOYDEN, GEORGE F HILTON, \\ LAWRENCE I LONN AND ARIAH SCHWARTZ
}

From the Department of Ophthalmology, University of California, San Francisco, and the Veterans Administration Medical Center, San Francisco, USA

SUMMARY We have used intraocular sulphur hexafluoride or liquid silicone as an adjunct to vitreous surgery in the treatment of a non-randomised sequential series of 19 eyes with retinal detachment complicated by proliferative vitreoretinopathy. We have studied the surgical results and complications of these two tamponades and drawn preliminary conclusions on their use in retinal reattachment surgery. After a seven-month minimum follow-up $13(68 \%)$ of the eyes have reattached retinas. Six $(60 \%)$ of 10 eyes treated only with silicone have reattached retinas, and four $(67 \%)$ of six eyes treated only with sulphur hexafluoride gas tamponade have reattached retinas. An additional three eyes treated initially with silicone oil subsequently developed retinal detachments; all were successfully reattached with sulphur hexafluoride tamponade after silicone oil removal. Intraoperative pneumatic retinal reattachment to assess relief of retinal traction combined with the production of widespread chorioretinal adhesions to wall off persistent anterior traction and detachment, as well as extended postoperative gas tamponade of the retina, appears to enhance the surgical results in retinal detachment complicated by proliferative vitreoretinopathy. Silicone oil tamponade of the retina appears to be useful in cases where retinal traction cannot be entirely relieved and in patients who are unable to tolerate the head positioning required for effective gas tamponade of the retina. A controlled clinical study recently begun will be required to define further the precise role of these methods of retinal tamponade.

Proliferative vitreoretinopathy (PVR) is the commonest cause of failure in retinal reattachment surgery, occurring in $5-10 \%$ of cases of retinal detachment' and accounting for irreparable loss of vision in approximately 1000 eyes in the United States each year. ${ }^{2}$ The proliferation of retinal pigment epithelial cells and glial cells on tissue surfaces within the eye, which is the hallmark of this disease, ${ }^{34}$ can present differing configurations of retinal detachment with differing surgical complexity, depending on the extent of involvement of the preretinal and subretinal surfaces, posterior vitreous face, and vitreous base.

Surgical techniques for the repair of these complex detachments have included scleral buckling, ${ }^{-57}$ liquid silicone, ${ }^{,-10}$ and vitrectomy in combination with a variety of techniques. These include membrane

Correspondence to Walter H Stern, MD, Department of Ophthalmology, U-490, 3rd and Parnassus Avenue, San Francisco, CA 94143, USA. dissection and intraocular gas tamponade, ${ }^{11}$ intraocular liquid silicone tamponade,,$^{12-14}$ and endolaser photocoagulation..$^{15}$ The evaluation and interpretation of surgical results with these different surgical techniques has been hampered by the lack of a uniform description of the type and complexity of the retinal detachments as well as the different surgical techniques that have been used.

We report the surgical results and complications of a non-randomised, sequential series of 19 eyes with proliferative vitreoretinopathy treated by vitreous surgery techniques combined with extended intraocular sulphur hexafluoride gas tamponade or liquid silicone tamponade.

\section{Materials and methods}

We reviewed the records of 19 consecutive patients (19 eyes) with retinal detachment complicated by proliferative vitreoretinopathy operated on by us from April 1983 to March 1984, with a minimum 
follow-up of seven months and a maximum follow-up of 20 months (average 11 months). There were 16 males and three females, with a mean age of 44 years. There were nine right eyes and 10 left eyes. Four of the patients were completely blind in the fellow eye. Thirteen $(68 \%)$ of the eyes were aphakic, five $(26 \%)$ of the eyes were phakic, and one $(5 \%)$ was pseudophakic. Eighteen (95\%) of the eyes had undergone previous scleral buckling and $12(65 \%)$ of the eyes had undergone previous vitrectomy surgery. Penetrating trauma was the cause of retinal detachment in three $(16 \%)$ of the eyes.

Eyes were graded preoperatively according to the Retina Society classification. ${ }^{16}$ A dense cataract allowed intraoperative classification only in one eye. The retinal detachment and vitreous anatomy were recorded with a retinal drawing, Tolentino crosssectional drawings, and $60^{\circ}$ fundus photographs. No pre-existing retinal breaks were identified preoperatively and intraoperatively in six $(32 \%)$ eyes. One break was identified in five $(26 \%)$ eyes, two breaks were identified in three $(16 \%)$ eyes, and three or more breaks were identified in five $(26 \%)$ eyes.

All eyes were operated on by one of us (WHS) in conjunction with other members of the Retinal Faculty at the University of California, San Francisco. A lensectomy was performed in four of the five phakic cases. In one eye in which silicone was used the clear lens was left in place. A pars plana vitrectomy was performed in all cases, including eyes that had previously undergone vitrectomy surgery, to relieve vitreoretinal traction and allow access to the retinal surface. Preretinal membranes were dissected and removed with forceps, and star folds were carefully opened when possible. Anterior folding of the retina towards the ora serrata (anterior loop contraction) was relieved by vitrectomy removal of as much of the residual vitreous base as possible followed by blunt separation of the anterior loop of the retina. In one eye a $90^{\circ}$ peripheral circumferential retinotomy was performed to relieve anterior loop contraction.

Subretinal fibrosis in four patients causing retinal elevation through the macula was treated by retinotomy followed by sectioning of the subretinal band. In two of these four patients with extensive subretinal fibrosis, peripheral relaxing or posterior relaxing retinotomies were performed.

Subretinal fluid was drained internally in 16 of the 19 eyes through a pre-existing break or intentional retinotomy on the superonasal side of the optic nerve. In three eyes with focal areas of retinal contraction, all of which had undergone previous vitrectomy surgery, a preoperative fluid-gas exchange was performed to achieve absorption of the subretinal fluid.
Of those cases tamponaded with silicone a siliconeair exchange was performed in eight and a siliconefluid exchange was performed in the remaining five. Dow-Corning medical grade 1000 centistoke liquid silicone was injected with an automated pneumatic pump either through the pars plana infusion terminal or through a 20 -gauge needle placed through the peripheral cornea while either the intraocular air or fluid was simultaneously aspirated.

In those cases receiving sulphur hexafluoride gas the air filled eye was perfused with $30 \mathrm{ml}$ of a $20 \%$ sulphur hexafluoride-air mixture through the infusion canula at the completion of the vitrectomy, with air exiting passively through an open sclerotomy.

Revision of the pre-existing scleral buckle was done in seven eyes. No revision was required in 11 eyes and a primary scleral buckle was performed in one eye. A broad high scleral buckle was obtained with a No. 279 solid grooved silicone implant or a 7.5 $\mathrm{mm}$ silicone sponge anchored to the sclera with two mattress sutures in each quadrant. Retinal breaks were treated either with argon laser endophotocoagulation or transscleral cryotherapy. Intraoperative endophotocoagulation of the retina overlying the scleral buckle, regardless of the identification of a retinal break, was performed $360^{\circ}$ in two eyes. Supplemental postoperative argon blue-green laser photocoagulation of the retina overlying the scleral buckle was performed in 11 eyes. A scatter photocoagulation pattern over the inferior retina was used in three patients with silicone tamponade.

Postoperative fluid-gas exchange with $20 \%$ to $60 \%$ sulphur hexafluoride gas (depending on the volume to be exchanged) was performed in all six gas filled eyes. In addition the retina in three silicone filled eyes redetached, and these eyes were treated by removal of silicone oil and replacement with sulphur hexafluoride gas tamponade. These eyes also required postoperative fluid-gas exchanges. The gas tamponade was maintained at $50 \%$ or greater of the intraocular volume for 14 to 21 days.

Silicone oil was removed from two eyes with reattached retinas and replaced with balanced salt solution. Silicone oil was not removed in the remaining five patients with reattached retinas owing to the patient's refusal to undergo further surgery as well as the anxiety of both patient and physician about a recurrent retinal detachment.

Retinal reattachment was defined as reattachment of the retina posterior to the scleral buckle.

\section{Results}

Thirteen $(68 \%)$ of the 19 eyes were successfully reattached, with a seven to 20-month follow-up 
period (average 11 months). Of these 13 eyes six $(46 \%)$ were successfully reattached with a single operation and seven (54\%) were successfully reattached with two or more operations (Table 1).

The PVR anatomic classification versus the retinal reattachment rate is summarised in Table 2.

Visual acuity results are summarised in Table 3.

Silicone oil was removed three months postoperatively from one eye with a reattached retina. This eye developed a recurrent retinal detachment that was not reoperated on. An additional eye underwent silicone oil removal six months after surgery, with the retina remaining attached.

\section{INTRAOPERATIVE COMPLICATIONS}

An unplanned retinal break occurred during membrane dissection in five $(26 \%)$ of 19 eyes.

In one eye extensive napkin ring subretinal fibrosis prevented retinal reattachment. Subretinal migration of silicone oil occurred in this patient owing to inadequate relief of retinal traction.

Table 1 Reoperations for recurrent retinal detachment

\begin{tabular}{|c|c|c|c|c|c|}
\hline & \multirow{2}{*}{$\begin{array}{l}\text { No. } \\
\text { eyes }\end{array}$} & \multicolumn{4}{|c|}{ Reattached } \\
\hline & & $\begin{array}{l}\text { Total } \\
(\%)\end{array}$ & $\begin{array}{l}\text { One } \\
\text { operation }\end{array}$ & $\begin{array}{l}\text { Two } \\
\text { operations }\end{array}$ & $\begin{array}{l}\text { Three } \\
\text { operations }\end{array}$ \\
\hline Silicone only & 10 & $6(60)$ & 4 & 2 & - \\
\hline Gas only & 6 & $4(67)$ & 2 & 2 & - \\
\hline $\begin{array}{l}\text { Silicone } \\
\text { followed by }\end{array}$ & & & & & \\
\hline gas & 3 & $3(100)$ & - & 2 & 1 \\
\hline Total & 19 & $13(68)$ & 6 & 6 & 1 \\
\hline
\end{tabular}

Table 2 Retinal reattachment rate and severity of PVR

\begin{tabular}{lll}
\hline Grade PVR & No. of eyes & No. $(\%)$ reattached \\
\hline C1 & 1 & $0(0)$ \\
C3 & 4 & $3(75)$ \\
D1 & 3 & $3(100)$ \\
D2 & 5 & $4(80)$ \\
D3 & 6 & $3(50)$ \\
\hline
\end{tabular}

Table 3 Final visual acuity in 13 cases with reattached retinas

\begin{tabular}{llll}
\hline Visual acuity & \multicolumn{2}{l}{ No. eyes } & \\
\cline { 2 - 4 } & With silicone & With gas & $\begin{array}{l}\text { With silicone } \\
\text { and gas }\end{array}$ \\
\hline $20 / 100$ & 1 & & \\
$5 / 200$ & 1 & 1 & 2 \\
$4 / 200$ & - & 1 & \\
$2 / 200$ & 2 & 2 & 1 \\
$\mathrm{HM}$ & 2 & - & \\
$\mathrm{LP}$ & - & & \\
\hline
\end{tabular}

$H M=$ hand movements. $L P=$ light perception.
POSTOPERATIVE COMPLICATIONS

Postoperative complications in 17 eyes with intraoperative retinal reattachment are listed in Table 4.

Recurrent proliferative vitreoretinopathy occurred in $12(71 \%)$ of 17 eyes successfully reattached at the time of surgery (Table 5).

Recurrent retinal detachment posterior to the scleral buckle occurred 11 times in 10 eyes (Table 4). No retinal breaks were identified in six $(60 \%)$ eyes. Old retinal breaks that had reopened were identified in three $(30 \%)$ eyes. New retinal breaks were identified in two $(20 \%)$ eyes. Within the group of 11 eyes in which the retina redetached recurrent proliferative vitreoretinopathy was noted in eight $(73 \%)$.

In six eyes treated initially with silicone the retina redetached, and all underwent reoperation with addition of silicone or replacement of silicone with gas. Five of these six eyes continued to remain attached.

Of the four eyes that were treated with gas tamponade initially in which the retina redetached, two were reoperated on. Anterior loop contraction was present in both eyes. No breaks were identified in either eye. A fluid-gas exchange resulted in retinal reattachment in both cases and was followed by extensive laser photocoagulation of the retina $360^{\circ}$

Table 4 Postoperative complications in 17 eyes with intraoperative retinal reattachment

\begin{tabular}{llll}
\hline \multicolumn{4}{l}{ No.eyes } \\
\cline { 2 - 4 } & $\begin{array}{l}\text { With } \\
\text { silicone (8) }\end{array}$ & $\begin{array}{l}\text { With } \\
\text { gas (6) }\end{array}$ & $\begin{array}{l}\text { With silicone } \\
\text { and gas (3) }\end{array}$ \\
\hline Recurrent proliferation & 3 & 6 & 3 \\
Recurrent retinal detachment & 6 & 4 & 1 \\
Angle closure glaucoma & 2 & - & - \\
Emulsification of silicone & 1 & - & - \\
Corneal decompensation & 3 & - & - \\
Hypotony & - & 1 & - \\
Fibrin pupillary membrane & 1 & 1 & - \\
\hline
\end{tabular}

Table 5 Recurrent proliferative vitreoretinopathy in 17 eyes with intraoperative retinal reattachment

\begin{tabular}{llll}
\hline & \multicolumn{2}{l}{ No. eyes } & \\
\cline { 2 - 4 } & $\begin{array}{l}\text { With } \\
\text { silicone (8) }\end{array}$ & $\begin{array}{l}\text { With } \\
\text { gas (6) }\end{array}$ & $\begin{array}{l}\text { With silicone } \\
\text { and gas (3) }\end{array}$ \\
\hline $\begin{array}{c}\text { Focal contraction (macular } \\
\text { pucker or extramacular } \\
\text { starfold) }\end{array}$ & 1 & 2 & 3 \\
$\begin{array}{c}\text { Anterior loop contraction only } \\
\begin{array}{c}\text { Combination focal and anterior } \\
\text { loop contraction }\end{array}\end{array}$ & - & 1 & - \\
$\begin{array}{c}\text { Widespread epiretinal } \\
\text { membranes }\end{array}$ & 1 & 2 & - \\
$\begin{array}{c}\text { Total no. eyes with recurrent } \\
\text { PVR }\end{array}$ & 3 & 6 & 3 \\
\hline
\end{tabular}


over the scleral buckle. The retina remained attached posterior to the scleral buckle, though residual fluid anterior to the scleral buckle is present in both cases.

Angle closure glaucoma occurred in one aphakic eye and one pseudophakic eye filled with silicone. Neither eye had a peripheral iridectomy performed at the time of surgery. The aphakic angle closure glaucoma was managed by performing an inferior peripheral iridectomy. The pseudophakic pupillary block was treated by first attempting a laser iridotomy nasally, which was unsuccessful in breaking the pupillary block, and later successfully treated by constricting the pupil with a topical miotic.

Emulsification of silicone in the anterior chamber without increase of intraocular pressure was observed in one patient three months after intraocular silicone injection. The silicone was removed uneventfully six months after injection and the eye continued to maintain a normal intraocular pressure and a reattached retina.

Silicone was not removed in five eyes with reattached retinas. Complications occurred in three of these five eyes and were limited to the cornea. Corneal oedema occurred in one eye and a linear subepithelial band opacity occurred in two eyes associated with corneal-silicone touch.

Neither the pseudophakic nor aphakic eyes with retained silicone developed sustained elevated intraocular pressure.

No complications were noted from intraocular gas injection.

\section{ANALYSIS OF FAILURES}

Inadequate relief of subretinal fibrosis contraction in one eye and epiretinal membrane contraction in another eye prevented intraoperative retinal reattachment in two of the six failed cases.

Widespread reproliferation of epiretinal membranes occurred in two eyes treated by extended gas tamponade and was associated with recurrent retinal detachment.

One eye developed an inferior retinal detachment under silicone oil after an extensive inferior retinotomy for release of subretinal fibrosis traction and was not reoperated on.

In one eye the retina redetached after removal of silicone oil.

Of the six failures, the preoperative Retina Society classification was C1 (one eye), C3 (one eye), D2 (one eye) and D3 (three eyes).

\section{Discussion}

Intraocular gas has occupied an increasingly important role in the treatment of retinal detachment since Rosengren ${ }^{17}$ described the use of air to tamponade retinal breaks and Norton ${ }^{18}$ described the use of sulphur hexafluoride to extend the intraocular gas tamponade. Cibis et al. ${ }^{8}$ and later Scott ${ }^{9}$ described an added dimension to the role of intraocular tamponades in retinal detachment with the use of liquid silicone to tamponade retinal breaks as well as to dissect epiretinal membranes.

The introduction of vitrectomy surgery and membrane dissection techniques by Machemer $e t a l .^{3}$ and, later, the addition of retinotomy techniques by Machemer ${ }^{19}$ and Zivojnovic et al. ${ }^{13}$ have encouraged the use of long-lasting internal tamponades not only to close breaks formed by vitreous traction and contractile cellular membranes, but also to close iatrogenic retinal breaks or retinotomies created at the time of vitreous surgery. Vitreous surgery techniques have, in addition, encouraged the use of vitreous substitutes such as liquid silicone and air to allow the intraoperative assessment of retinal traction. ${ }^{20}$

We have evaluated the role of liquid silicone or extended sulphur hexafluoride gas tamponade in combination with vitreous surgery and pneumatic retinal reattachment in the management of proliferative vitreoretinopathy. From this experience we have attempted to draw conclusions on the surgical management of PVR.

One of the most important surgical steps was the ability to assess relief of retinal traction intraoperatively. In 16 eyes intraoperative pneumatic retinal reattachment, by draining subretinal fluid through a pre-existing break or through an iatrogenic retinotomy while infusing air with an automated pump, allowed this crucial determination. In three eyes with previous vitrectomy surgery, preoperative fluid-gas exchange indicated the location and extent of the additional membrane dissection that was required to achieve adequate retinal reattachment. If we consider only those eyes in which we could achieve adequate retinal reattachment intraoperatively, we achieved long term anatomical success in $13(76 \%)$ of 17 eyes.

The instillation of liquid silicone and assessment of retinal traction has been modified by different authors. Scott ${ }^{9}$ combined external drainage of subretinal fluid with the instillation of intraocular silicone. He used indirect ophthalmoscopy to monitor residual retinal traction and subretinal silicone migration. Zivojnovic et al..$^{13}$ and Gonvers ${ }^{14}$ have used silicone-fluid exchange under microscopic control combined with internal drainage of intraocular and subretinal fluid to assess retinal traction.

Techniques for fluid-gas exchange at the time of vitrectomy or prior to vitrectomy have also undergone modification. Charles ${ }^{20}$ described hydraulic 
retinal reattachment for proliferative vitreoretinopathy. The use of an automated air infusion pump $^{21}$ to maintain a constant intraocular pressure, combined with improved visualisation in the air-filled eye using sodium hyaluronate on the corneal endothelium ${ }^{22}$ and a biconcave lens ${ }^{23}$ in the phakic airfilled eye, have enhanced pneumatic retinal reattachment techniques. Fluid-gas exchange techniques in eyes that have previously undergone vitrectomy surgery ${ }^{24}$ have further enhanced preoperative and postoperative pneumatic retinal reattachment.

We used two different techniques for the instillation of silicone in the present study. In five eyes we performed a silicone-fluid exchange. In the remaining eight eyes we first attached the retina with air before filling the eye with silicone. The advantage of a fluid-silicone exchange is the ability to dissect epiretinal membranes when the retina is stretched by the silicone bubble. The major disadvantage is the tendency for silicone to migrate into the subretinal space if retinal traction is unrelieved and the difficulty both in visualising and treating this complication. Intraoperative pneumatic retinal reattachment using an automated air infusion pump to maintain a constant intraocular pressure, and the use of sodium hyaluronate applied to the corneal endothelium to achieve a clear view of the fundus, allow a variety of intraocular manipulations, including membrane dissection, retinotomy, and endolaser photocoagulation. Although subretinal migration of air and enlargement of retinal breaks are complications of this procedure, they are readily treated. In no case in this series did we infuse silicone into the subretinal space after successful pneumatic retinal reattachment. We were therefore able to avoid a major complication associated with silicone injection. ${ }^{10}$

The role of a broad scleral buckle in the treatment of PVR has been emphasised recently. ${ }^{152526} \mathrm{We}$ found a broad buckle helpful in treating residual anterior loop contraction following vitrectomy and membrane dissection. A broad buckle was also helpful for recurrent detachment where it was possible to isolate anterior loop contraction and residual retinal detachment, with barrier photocoagulation on the scleral buckle after fluid-gas exchange.

The role of intraoperative laser endophotocoagulation in the treatment of retinal detachment and proliferative vitreoretinopathy has been emphasised. ${ }^{\text {is }}$ This form of treatment was extremely helpful in those cases where the scleral buckle was not revised as well as for large retinotomies and posterior retinal breaks, both in the air filled and silicone filled eye. Intraoperative or postoperative photocoagulation of the retina overlying the scleral buckle $360^{\circ}$ appears to be justified in view of the success we had in treating recurrent retinal detach- ments due to anterior loop contraction in silicone filled eyes and gas filled eyes.

The corneal complications noted in our aphakic patients treated with silicone have been described by other authors ${ }^{10}$ and are presumably due to blocking aqueous nutrition of the corneal endothelium. ${ }^{27}$

Evaluation of retinal toxicity from silicone requires further detailed studies. In this study the best vision $(20 / 100)$ resulted in a patient with intraocular silicone maintained for a six-month period. Recent electroretinographic (ERG) studies in patients with giant retinal tears treated with intraocular silicone versus sulphur hexafluoride gas appear to demonstrate the lack of short term retinal toxicity from silicone. ${ }^{28} \mathrm{We}$ have not noted unexplained visual deterioration in five patients with intraocular silicone ranging from seven months to 17 months, average 13 months.

If useful vision is defined as $5 / 200$ vision or greater visual acuity, only four eyes out of 13 eyes that remain reattached achieved this level of acuity. In certain cases the macular distortion caused by epiretinal and subretinal membranes was an obvious, though not exclusive, source of the decreased vision. In other cases the macula appeared normal and we suspect a variety of other factors, such a poor photoreceptor regeneration following recurrent retinal detachments, as the source of the poor vision. ${ }^{29}$

It is difficult to compare the anatomical reattachment rates in those eyes treated with silicone versus those eyes treated with gas for several reasons. First, silicone oil was removed electively in only two of 13 patients. A more valid comparison would require removal of silicone oil in all eyes to approximate the gradual loss of intraocular tamponade by reabsorption of intraocular gas. Secondly, we switched to a gas tamponade in three eyes in which the retina became detached under silicone oil. Lastly, silicone oil was used in two eyes in which intraoperative pneumatic retinal reattachment was unsuccessful, whereas sulphur hexafluoride was used only after successful pneumatic retinal reattachment. Gonvers ${ }^{14}$ reported a $62 \%$ anatomical success rate persisting after removal of silicone oil in eyes with PVR treated with vitrectomy and silicone oil. However, he did not reoperate on any eyes with recurrent retinal detachment under the silicone tamponade, a procedure which might have increased his anatomical success rate. Zivojnovic et al. ${ }^{13}$ reported a $57 \%$ long term (two to four years) anatomical success rate using liquid silicone in combination with vitrectomy. Silicone was removed in $10 \%$ of cases and reoperation was performed with reinjection of silicone in $31 \%$ of cases. Removal of silicone resulted in redetachment in one-third of the cases.

In the present study seven ( $78 \%$ ) of nine eyes were 
successfully treated with extended gas tamponade. Chang and coauthors have recently reported a $56 \%$ anatomical success rate for PVR using perfluoropropane to provide an extended gas tamponade following vitreous surgery." An advantage of perfluoropropane over sulphur hexafluoride is the reduced number of postoperative gas-fluid exchanges necessary to maintain an effective tamponade. In the present study it was necessary to perform an average of three fluid gas exchanges in the postoperative period to maintain a gas bubble of $50 \%$ or greater of the intraocular volume for a three-week period. We injected additional aliquots of sulphur hexafluoride postoperatively that ranged from $20 \%$ to $60 \%$ without significant increases of intraocular pressure. We did not, however, perform total fluid gas exchanges, since the patients were seated at the slit-lamp and inferior intraocular fluid was never totally drained. This allowed room for expansion of the gas bubble when the concentration of sulphur hexafluoride exceeded $20 \%$.

In three cases treated with gas tamponade that developed recurrent retinal detachment outpatient fluid-gas exchange accompanied by focal laser to the retinal break or widespread laser to the scleral buckle was sufficient to reattach the retina. In appropriate post-vitrectomy patients fluid-gas exchange accompanied by laser therapy, even when the retinal break cannot be visualised, may provide an effective means of reattaching the retina. If this procedure is successful, it eliminates the need for general anaesthesia and further intraocular surgery or scleral buckling.

De Bustros and Michels have stressed the biological time course of the proliferative process in PVR and suggested delaying intraocular surgery for six or more weeks. ${ }^{26}$ We performed intraocular surgery after an average interval of 2.9 months (range one to seven months) from previous operations. This allowed time for the epiretinal membranes to become thicker and easier to grasp as well as allowing the proliferative and contractile process to stabilise. Nevertheless, reproliferation continues to be a problem.

Recurrent PVR occurred in $12(71 \%)$ of 17 reattached retinas and was associated with eight of the 11 recurrent retinal detachments. The high percentage of eyes with recurrent PVR following vitrectomy has been emphasised by Machemer and Zivojnovic et al. Machemer, ${ }^{19}$ using vitrectomy and gas tamponade, reported an initial reattachment rate of $68 \%$ to 47 eyes operated on for PVR, which decreased to $36 \%$ reattachment rate after six months. Zivojnovic et al.,$^{13}$ using vitrectomy and silicone tamponade, reported a three-month reattachment rate of $66 \%$ in 100 eyes, which subsequently decreased to $57 \%$ reattachment after a two- to four- year follow-up. The continued proliferation and contraction of intraocular cells emphasises the need for pharmacological treatment in these cases. ${ }^{31}$

Pneumatic retinal reattachment techniques have improved to allow intraocular surgical manipulations that previously were possible only in silicone filled eyes. Liquid silicone does not appear to be a highly effective tamponade for inferior retinal breaks and may cause ocular complications if not removed. Nevertheless, in patients who cannot tolerate the head positioning associated with gas tamponade, and in cases where retinal traction cannot be entirely relieved, silicone appears to be a useful intraocular tamponade. This description of surgical experiences emphasises the need for a prospective, randomised clinical trial to compare these two methods of tamponade. Such a study is under way.

\section{References}

1 Haiman MH, Burton TC, Brown CK. Epidemiology of retinal detachment. Arch Ophthalmol 1982; 100: 289-92.

2 Ryan SJ. Proliferative vitreoretinopathy (Editorial). Am J Ophthalmol 1985; 99: 593-5.

3 Machemer R, Van Horn DL, Aaberg TM. Pigment epithelial proliferation in human retinal detachment with massive periretinal proliferation. Am J Ophthalmol 1978; 85: 181-91.

4 Van Horn DL, Aaberg TM, Machemer R, Fenzl R. Glial cell proliferation in human retinal detachment with MPP (massive periretinal proliferation). Am J Ophthalmol 1977: 84: 383-93.

5 Havener WH. Massive vitrcous retraction. Int Ophthalmic Surg 1976; 16: 135-55.

6 McPherson A. Mowa R. Full thickness scleral buckling with cryoapplication and silicone sponge in retinal detachment surgery: a review of 447 cases. In: Pructt RC. Regan CDJ, cds. Retina congress. New York: Appleton Century Crofts, 1974: 325-53.

7 Grizzard WS, Hilton GF. Scleral buckling for retinal detachment complicated by periretinal proliferation. Arch Ophthalmol 1982; 100: 419-22.

8 Cibis PA, Becker P, Okun E, Canaan S. The use of liquid silicone in retinal detachment surgery. Arch Ophthalmol 1962; 68: $590-9$.

9 Scott JD. Treatment of the detached immobile retina. Trans Ophthalmol Soc UK 1972; 92: 351-7.

10 Grey RHB, Leaver PK. Silicone oil in the treatment of massive periretinal retraction: results in 105 cyes. Br J Ophthalmol 1979; 63: 355-60.

11 Machemer R. Laqua $H$. A logical approach to the treatment of massive perirctinal proliferation. Ophthalmology (Rochester) 1978; 85: 584-93.

12 Haut J, Ullern M, Boulard ML. Cedak A. Utilisation du silicone intra-oculaire après vitrectomic comme traitement des retractions massives du vitre. Note preliminaire. Bull Soc Ophtalınol Fr 1978; 78: 361-5.

13 Zivojnovic R, Mertens DAE, Peperkamp E. Fluid silicon in amotio surgery. II: Report on 280) cases. Further developments in technique. Klin Monatsbl Augenheilkd 1982: 181: 444-52.

14 Gonvers $M$. Temporary silicone oil tamponade in the management of retinal detachment with proliferative vitreoretinopathy. Am J Ophthalmol 1985; 100: 239-45.

15 Parke DW II, Aaberg TM. Intraocular argon laser photocoagulation in the management of severe proliferative vitrcoretinopathy. Am J Ophthalmol 1984; 97: 434-43.

16 Retina Society Terminology Committee. The classification of 
retinal detachment with proliferative vitreoretinopathy. Ophthalmology (Rochester) 1983; 90: 121-5.

17 Rosengren B. Cases of retinal detachment treated with diathermy and injection of air into the vitreous body. Acta Ophthalmol (Kbh) 1938; 16: 3-42.

18 Norton EWD. Intraocular gas in the management of selected retinal detachments. Ophthalmology (Rochester) 1972; 77: 95-8.

19 Machemer R. Retinotomy. Am J Ophthalmol 1981; 92: 768-74.

20 Charles S. Vitreous microsurgery. Baltimore: Williams and Wilkins, 1981: 126-7.

21 Brucker AJ, Hoffman ME, Nevyas HJ, Wulc AE. New instrumentation for fluid-air exchange. Retina 1983; 3: 135-6.

22 Landers MB III. Sodium hyaluronate as an aid to internal fluidgas exchange. Am J Ophthalmol 1982; 94: 557-9.

23 Landers MB III, Stefansson E, Wolbarsht ML. The optics of vitreous surgery. Am J Ophthalmol 1981; 91: 611-4.

24 Stern WH, Blumenkranz MS. Fluid-gas exchange after vitrectomy. Am J Ophthalmol 1983; 96: 400-2.

25 Jalkh AE, Marcos PA, Schepens CL, Azzolini C, Duncan JE, Trempe CL. Surgical treatments of proliferative vitreoretinopathy. Arch Ophthalmol 1984; 102: 1135-9.
26 De Bustros S, Michels RG. Surgical treatment of retinal detachments complicated by proliferative vitreoretinopathy. Am J Ophthalmol 1984; 98: 694-9.

27 Sternberg P, Hatchell DL, Foulks GN, Landers MB III. The effect of silicone oil on the cornea. Arch Ophthalmol 1985; 103: 90-4.

28 Frumar KZ, Arden GB. Electrophysiologic responses after vitrectomy and intraocular tamponade; a prospective study. Invest Ophthalmol Vis Sci 1984; 25 (suppl): 308.

29 Cleary PE, Leaver PK. Macular abnormalities in the reattached retina. Br J Ophthalmol 1978; 62: 595-603.

30 Chang S, Coleman DJ, Lincoff $H$, Wilcox LM jr, Braunstein RA, Maisel JM. Perfluoropropane gas in the management of proliferative vitreoretinopathy. Am J Ophthalmol 1984; 98: 180-8.

31 Stern WH, Lewis GP, Erickson PA, Anderson DH, Fisher SK, O'Donnell JJ. Fluorouracil therapy for proliferative vitreoretinopathy after vitrectomy. Am J Ophthalmol 1983; 94: 33-42.

Accepted for publication 7 March 1986. 